\title{
Evaluation of DNA methylation of inflammatory genes following treatment of chronic periodontitis: A pilot case- control study
}

\author{
Farah Asa'ad ${ }^{1}$ (D) | Valentina Bollati ${ }^{2,3}$ (D) | Giorgio Pagni ${ }^{1}$ (D) | Rogerio M. Castilho ${ }^{4,5}$ | \\ Eleonora Rossi ${ }^{1}$ | Francesca Pomingi ${ }^{6}$ | Letizia Tarantini ${ }^{2}$ | Dario Consonni ${ }^{3}$ (D) | \\ William V. Giannobile ${ }^{5}$ (D) | Giulio Rasperini ${ }^{1}$ (D)
}

${ }^{1}$ Department of Biomedical, Surgical and Dental Sciences, Fondazione

IRCCS Ca' Granda Ospedale Maggiore

Policlinico, University of Milan, Milan, Italy

${ }^{2}$ EPIGET-Epidemiology, Epigenetics and Toxicology Lab, Department of Clinical

Sciences and Community Health, University of Milan, Milan, Italy

${ }^{3}$ Epidemiology Unit, Fondazione IRCCS Ca' Granda Ospedale Maggiore Policlinico, Milan, Italy

${ }^{4}$ Laboratory of Epithelial Biology, University of Michigan School of Dentistry, Ann Arbor, MI, USA

${ }^{5}$ Department of Periodontics and Oral Medicine, School of Dentistry, University of Michigan, Ann Arbor, MI, USA

${ }^{6}$ Private Practice, Piacenza, Italy

Correspondence

Giulio Rasperini, Department of Biomedical, Surgical and Dental Sciences, Fondazione IRCCS Ca' Granda Ospedale Maggiore Policlinico, University of Milan, Milan, Italy. Email: giulio.rasperini@unimi.it

Funding information

This study was self-supported. This study was presented in part at the Italian Society of Periodontology Meeting and received the Goldman Research Prize to FA in 2017

\begin{abstract}
Objective: To evaluate the influence of periodontal therapy on DNA methylation in patients with chronic periodontitis as compared to healthy individuals.

Material and Methods: Twenty patients were enrolled into two groups: (i) 10 diagnosed as clinically healthy; and (ii) 10 diagnosed with chronic periodontitis. Clinical measures were recorded and gingival biopsies were harvested at baseline (both patient groups) and at 2 and 8 weeks post-baseline for diseased individuals. Molecular DNA methylation analysis was performed by pyrosequencing for the putative inflammation-associated genes LINE-1, COX-2, IFN- $\gamma$ and TNF- $\alpha$. Random-intercept linear regression models were applied to evaluate methylation levels across groups at baseline and the methylation changes over time in the diseased and normal tissues.

Results: Periodontal therapy did not influence gene expression methylation of TNF- $\alpha$, IFN- $\gamma$ and LINE-1 levels at normal and periodontitis sites over time. However, it significantly reduced COX-2 methylation levels comparable to healthy individuals at both 2 and 8 weeks post-treatment $(p<.05)$.

Conclusions: Periodontal therapy resets the DNA methylation status of inflammatory gene for COX-2 in patients with periodontal disease. DNA methylation levels of TNF$\alpha$, IFN- $\gamma$ and LINE- 1 were sustained in periodontitis sites despite therapy. Future studies should consider an expanded panel of inflammatory genes over time. (ClinicalTrials. gov NCT02835898).
\end{abstract}

KEYWORDS

biomarkers, DNA methylation, epigenetics, inflammatory genes, periodontal disease pathogenesis, periodontal diseases/therapy

\section{1 | INTRODUCTION}

Periodontitis is a destructive disease of the tooth-supporting tissues induced by bacterial biofilm (Van Dyke \& van Winkelhoff, 2013) that eventually triggers an inflammatory host response influenced by environmental, genetic and epigenetic factors (Borrell \& Papapanou,
2005; Kornman, 2008; Takashiba \& Naruishi, 2006). Of interest to this study, epigenetic modification can further regulate gene expression of an individual's immune response (Schulz et al., 2016), and despite the well-established influence of epigenetic modification in cancer and inflammatory diseases (Adcock, Tsaprouni, Bhavsar, \& Ito, 2007; El Gazzar, Yoza, Hu, Cousart, \& McCall, 2007; Fitzpatrick \& Wilson, 2003; 
Ngollo et al., 2014) little is known in the context of oral health (Lod, Johansson, Abrahamsson, \& Larsson, 2014). In general, epigenetics embodies the modifications of gene expression, without changing the DNA sequence (Adcock et al., 2007; Bird, 2002) through chemical alterations of DNA and associated proteins (Barros \& Offenbacher, 2014) that evoke chromatin remodelling and a successive rapid inactivation or activation of genes (Larsson, Castilho, \& Giannobile, 2015). Notably, such alterations occur through two major mechanisms in human cells (Shaw, 2006); DNA methylation and histone modifications (Wilson, 2008) with the former offering a more stable form of gene regulation (Bäckdahl, Bushell, \& Beck, 2009). Accordingly, most of the studies exploring the link between epigenetics and periodontal disease have investigated the changes in the DNA methylation of genes involved in the regulation of cytokine production, as these signalling molecules play a key role in periodontal tissue breakdown; for reviews see: Barros \& Offenbacher, 2014; Lod et al., 2014; Larsson et al., 2015;. Recent studies in experimental periodontitis have also demonstrated the activation of inflammatory routes including the NFKB signalling pathway by histone modifications (Martins et al., 2016). Several studies demonstrated a lower level of DNA methylation of genes expressing pro-inflammatory cytokines in patients with periodontitis, either chronic or aggressive, compared to those with a healthy periodontium (Andia et al., 2010; Ishida et al., 2012; Oliveira et al., 2009; Zhang, Crivello, et al., 2010). Nevertheless, hypermethylation has been also described for specific genes in the chronic state of periodontal disease, as a downregulatory mechanism to prevent unrestricted tissue destruction (Zhang, Barros, et al., 2010). Likewise, higher DNA methylation in chronic periodontitis has been also reported in recent studies (Kojima et al., 2016; Zhang et al., 2013). Although several epigenetic alterations have been described in periodontal disease, little is known about the efficacy of periodontal therapy in re-establishing normal DNA methylation levels in patients. The prospective positive effects of periodontal therapy on the methylation profile of DNA and specific genes came from the study of Andia et al. (2015) that found no change between healthy and periodontitis tissues after 3 months. These findings suggest that periodontal therapy can influence epigenetic modifications. However, variations in the methylation level between both groups were not assessed at baseline and samples of inflamed tissues were not investigated.

Based on these observations, we conducted a clinical study to monitor the changes in DNA methylation of long interspersed nuclear element-1 (LINE-1), cyclooxygenase-2 (COX-2), interferon gamma $(\mathrm{IFN}-\gamma)$ and tumour necrosis factor alpha (TNF- $\alpha$ ) inflammatory genes in periodontitis patients following periodontal therapy in comparison with healthy subjects at both the site and patient levels.

\section{2 | MATERIALS AND METHODS}

This investigation was approved by the ethical committee of the University of Milan, Italy, and was conducted during the period between October 2015 and June 2016. This short-term, prospective cohort study is registered at ClinicalTrials.gov (Identifier: NCT02835898).

\section{Clinical Relevance}

Scientific rationale for the study: Little is known about the influence of periodontal therapy on DNA methylation levels in patients with chronic periodontitis.

Principal findings: Periodontal therapy is able to reset the levels of COX-2 methylation to compatible levels observed in healthy patients on the short-term. Methylation profile from normal tissues of patients with periodontitis suggests they might be more prone to periodontal tissue breakdown.

Practical implications: Local effects of the disease have an influence on the epigenetics of the tissues that may be modulated by the microbiota. Findings might help to better elucidate disease development in healthy sites of patients with periodontitis.

\section{1 | Study participants and inclusion criteria}

From the pool of patients attending a private dental practice in Piacenza-Italy, twenty individuals were enrolled equally in two groups: 10 healthy patients displaying a disease-free periodontium and 10 moderatepatients with chronic periodontitis, as the present clinical investigation is considered a pilot investigation. All participants were voluntarily enrolled into the study after explaining its objectives and obtaining their verbal and written informed consent.

Study participants fit the following inclusion criteria:

1. Patients 18 years of age or older.

2. Patients without any reported systemic diseases.

3. Non-smokers or ex-smokers who had quit smoking for at least one or more years prior to enrolment in the study.

4. Patients of Caucasian origin.

5. For the healthy group: patients who showed no clinical signs of gingival inflammation or history of periodontitis were included. In this group, periodontal probing depths (PPD) in all sites were $\leq 3 \mathrm{~mm}$, without any signs of tooth mobility, bleeding on probing (BOP) or clinical attachment loss (CAL).

6. For the periodontal disease group: patients diagnosed with chronic periodontitis according to the American Academy of Periodontology (AAP) Workshop definition (Armitage, 1999) were included. Patients in this group displayed a minimum of a single "healthy site" (PPD $<4 \mathrm{~mm}$ without signs of bleeding on probing, mobility or inflammation) and a periodontitis site (PPD $\geq 5 \mathrm{~mm}$ with bleeding on probing at baseline) for subsequent biopsy harvesting.

The exclusion criteria were the following:

1. Pregnant patients.

2. Patients who reported the use of antibiotics and/or non-steroidal anti-inflammatory drugs (NSAIDs), for at least 1 month before enrolment in the study. 
3. Patients who received periodontal therapy within the last 3 months prior to enrolment in the study.

\subsection{Study timeline and periodontal parameters}

\subsection{1 | Baseline}

For periodontitis participants, periodontal probing depth (PPD), clinical attachment level ( $C A L$ ), bleeding on probing (BOP), full-mouth plaque score (FMPS) and full-mouth bleeding score (FMBS) were recorded at six sites around each tooth. As for healthy patients, only periodontal screening and recording (PSR) was registered, in accordance with the principles of good clinical practice; the periodontal charting is completed when the patient presents with two or more sites of a PD $\geq 5 \mathrm{~mm}$ (Tonetti \& Claffey, 2005).

Next, gingival biopsies were obtained from the healthy patients during surgical removal of wisdom teeth, using a 3-mm diameter punch. In the periodontal disease group, biopsies were harvested from two sites: a normal site and a periodontitis site with the purpose to compare methylation levels between both clinically distinct sites. Following biopsy harvest, patients with chronic periodontitis underwent conventional periodontal therapy consisting of full-mouth scaling and root planing with ultrasonic and manual instruments. Chlorhexidine mouthwash $(0.2 \%)$ was prescribed for daily use (twice daily for 20 days).

\subsection{2 | Two and eight weeks after periodontal therapy}

PPD, CAL \& BOP, FMPS \& FMBS were measured and gingival biopsies were harvested for the disease group only, from both a normal and a periodontitis site, to analyse the influence of periodontal therapy on epigenetic modifications as comparison to each time point. Two weeks point of time was selected to evaluate the early response to periodontal treatment, while 8 weeks was chosen because the re-evaluation of periodontal parameters after periodontal therapy varies between 4 and 8 weeks (ideally 4-6 weeks). However, 4 and 6 weeks points of time might be a little bit short for adequate stability of periodontal parameters, therefore, 8 weeks was chosen as a reasonable point of time as a first re-evaluation following periodontal therapy (Segelnick \& Weinberg, 2006).

In the periodontitis group, it was not possible to harvest biopsies from the same site at different points of time, therefore, tissue sampling was carried out in a manner to match the clinical parameters at all points of time as the following: for healthy sites, PPD $<4 \mathrm{~mm}$ without bleeding on probing or signs of inflammation at all points of time. For periodontitis sites, PPD $\geq 5 \mathrm{~mm}$ with bleeding on probing at baseline. For 2 and 8 weeks point of time, biopsies were harvested from sites of $\mathrm{PPD} \geq 5 \mathrm{~mm}$ without bleeding on probing but already showed BOP at baseline, as documented in the periodontal chart.

A single calibrated examiner made the measurements and harvested the gingival biopsies (GR), while the same experienced dental hygienist (FP) performed the conventional periodontal therapy on all patients of the periodontitis group.

\subsection{Sample collection, DNA extraction and bisulphite treatment}

Briefly, freshly harvested tissues were collected and submerged in Allprotect Tissue Reagent (Qiagen, USA) to stabilize DNA immediately and were stored in vials at $2-8^{\circ} \mathrm{C}$ for up to 6 months. DNA was extracted using the QIAamp DNA Mini Kit (Qiagen) according to the manufacturer's recommendations.

EZ DNA Methylation-Gold ${ }^{\text {Tm }}$ Kit (Zymo Research, Orange, CA, USA) was used to treat $500 \mathrm{ng}$ DNA (concentration $25 \mathrm{ng} / \mu \mathrm{l}$ ) according to the manufacturer's protocol. Bisulphite-treated DNA was eluted in $300 \mu$ l of M-Elution Buffer.

\section{4 | Analysis of DNA methylation}

Analysis of DNA methylation was performed using previously published methods (Bollati et al., 2007; Tarantini et al., 2013) with minor modifications. Briefly, a $50 \mu \mathrm{l}$ PCR reaction was carried out in $25 \mu \mathrm{l}$ of GoTaq Hot Start Green Master Mix (Promega, Madison, WI, USA), 1 pmol of the forward primer, 1 pmol of the biotinylated reverse primer, $25 \mathrm{ng}$ of bisulphite-treated genomic DNA and water. Primers used for DNA methylation analysis and PCR cycling conditions are shown in Table 1. The biotin-labelled primers were used to purify the final PCR product using Sepharose beads. The PCR product was bound to Streptavidin Sepharose HP (Amersham Biosciences, Uppsala, Sweden) and the Sepharose beads containing the immobilized PCR product were purified, washed, denatured using a $0.2 \mathrm{~mol} / \mathrm{L} \mathrm{NaOH}$ solution and washed again using the Pyrosequencing Vacuum Prep Tool (Pyrosequencing Inc., Westborough, MA, USA), as recommended by the manufacturer. Then, $0.3 \mu \mathrm{l}$ pyrosequencing primer was annealed to the purified single-stranded PCR product, and pyrosequencing was performed using the PyroMark MD System (Pyrosequencing Inc.). The degree of methylation was expressed as a percentage of methylated cytosines divided by the sum of methylated and unmethylated cytosines (\%5 mC).

The CpG positions were selected according to data published in literature for the same assessed genes (Dawsey et al., 2008; Madrigano et al., 2012; Cantone et al., 2017), which ensures consistency in terms of repeatability of the assay.

\section{5 | Statistical analysis}

To compare gender and age distribution between the two groups, we use the chi-square and the Wilcoxon-Mann-Whitney test, respectively. To take into account correlations within subjects, random-intercept linear regression models were applied to evaluate methylation levels across groups at baseline and to evaluate methylation changes over time in the periodontal disease group, separately for the disease-free and periodontitis sites. Statistical analyses were performed with Stata 13 (StataCorp. 2013; RabeHesketh \& Skrondal, 2008). Statistical significance was set at $p$ value $<.05$. 


\section{3 | RESULTS}

Twenty participants (8 males, 12 females) were included in this study, distributed into "healthy" ( 5 males, 5 females) and "periodontal disease" groups ( 3 males, 7 females). The age in the healthy group was between 25 and 69 years old (mean $=53.3 \pm 12.3$ years), while the range was $26-60$ years old in the periodontal disease group (mean $=46.6 \pm 10$ years). Nineteen of the initial 20 participants completed the study with one dropout at the 8th week (Figure 1).

Periodontal therapy in the periodontal disease group was successful based on the changes in the mean of PPD, CAL \& BOP over time. Mean PPD at baseline was $4.2 \pm 0.4 \mathrm{~mm}$, which became $2.5 \pm 0.3 \mathrm{~mm}$ on 8 th week $(p<.001)$. In the healthy group, PPD at baseline in all sites was $\leq 3 \mathrm{~mm}$. Clinical attachment level in the periodontitis group was $4.2 \pm 0.9$ at baseline, indicating a moderate periodontal disease. Eight weeks post-therapy, mean CAL became $3.6 \pm 0.9 \mathrm{~mm}(p=.01)$. As for bleeding on probing, mean percentage at baseline was $63 \%$ in periodontally diseased individuals and decreased up to $5 \%$ at the end of the evaluation period $(p<.001)$.

Demographic and clinical characteristics of the study sample are shown in Table 2, while Table 3 reports clinical characteristics of the harvested sites in the periodontitis group at the time of biopsy. A marked improvement in PPD of periodontitis sites from which biopsies were harvested can be noted at 2 and 8 weeks $(p<.001)$. Due to site selection characteristics, sites affected by periodontal disease must have had BOP at baseline while healthy sites in patients with periodontitis must not have had BOP at baseline. For 2 and 8 weeks point of time, BOP greatly reduced in all sites of the mouth following periodontal therapy. Therefore, it was possible to harvest biopsies from sites that showed no BOP at these points of time, but had BOP at baseline as documented in the periodontal chart.

Regarding DNA methylation of TNF- $\alpha$ gene, the promoter region was more methylated in healthy individuals $(36.6 \% \pm 9.2)$, compared to normal \& periodontitis sites of the periodontal disease group $(34.1 \% \pm 5.2$ and $31.4 \% \pm 7.8$, respectively), indicating a relatively more active gene expression of TNF- $\alpha$ in the state of disease. Methylation status remained almost stable in normal sites throughout the evaluation period. In the periodontitis sites, however, methylation level was almost stable up to 2 weeks. Afterwards, it started to rise reaching $33.7 \% \pm 7.4$ at 8 weeks, which is quite close to that reported in normal sites at baseline. Nonetheless, these results were not statistically significant ( $p$-value $>.05$ ), neither among groups nor among sites.

As for the promoter region of IFN- $\gamma$ gene, it was hypermethylated among all entities, with the healthy group displaying the highest methylation percentage among all $(88.6 \% \pm 1.4)$ reflecting a decreased gene expression of IFN- $\gamma$ in the state of periodontal health. Regarding the periodontal disease group, the level of methylation in periodontitis sites was almost comparable to healthy individuals $(88.3 \% \pm 2.1)$, while normal sites exhibited a slightly lower methylation $(85.8 \% \pm 6.5)$. Through time, DNA methylation in periodontitis sites started to decline, reaching at 8 weeks a percentage almost equivalent to that reported in normal sites at baseline $(86.2 \% \pm 3.8)$. 


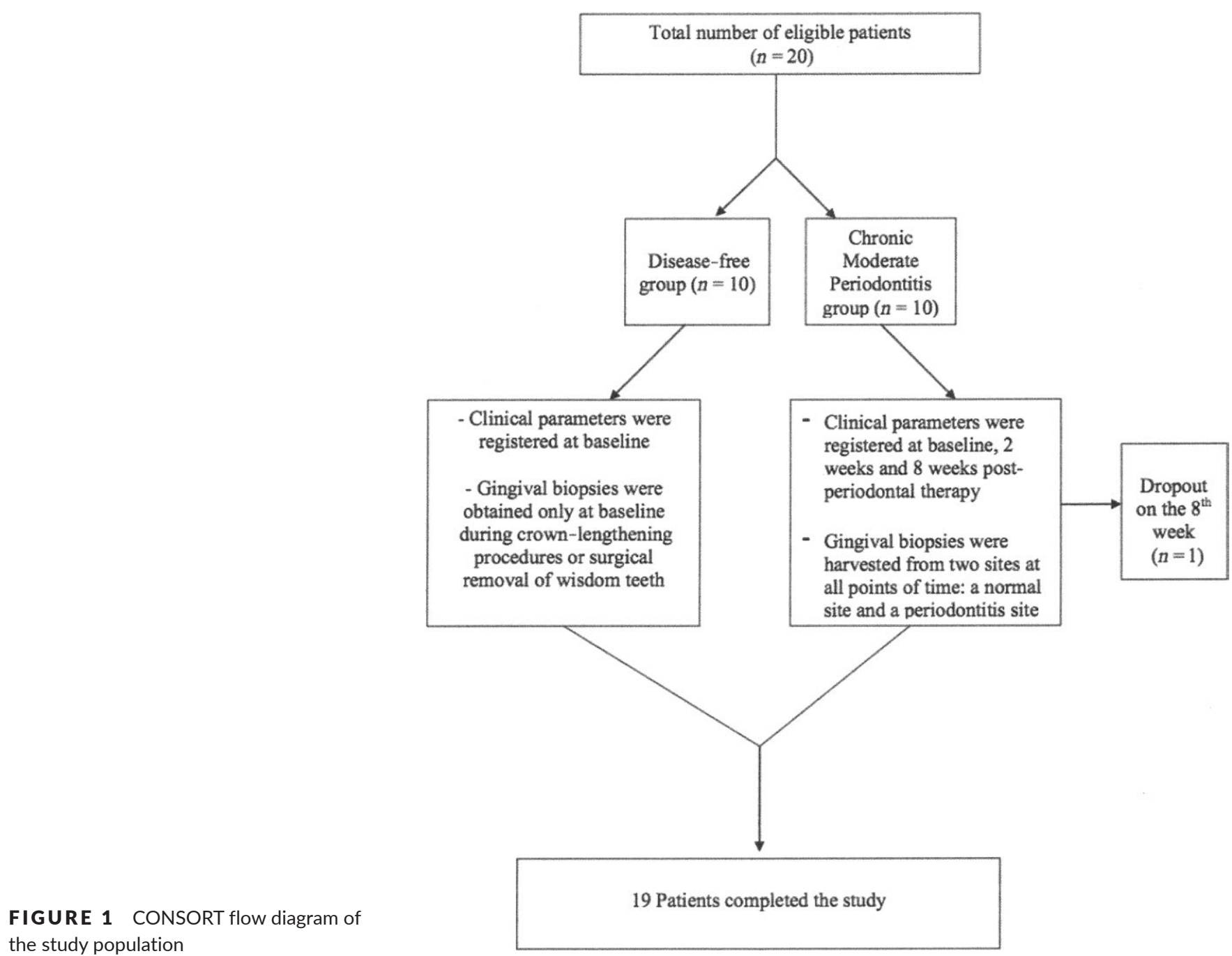

the study population

On the other hand, methylation levels started to increase in normal sites, approaching a level at 8 weeks comparable to the healthy group $(88.8 \% \pm 2.8)$. None of these findings was statistically significant ( $p$ value $>.05)$.

\section{1 | Periodontal therapy reduces the methylation of COX-2 promoter}

Unlike TNF- $\gamma$ and IFN- $\gamma$, COX-2 promoter region was hypomethylated in periodontium of healthy patients $(6.7 \% \pm 7.6)$. DNA methylation was nearly as twice as high in the periodontitis sites $(13.2 \% \pm 7.3)$, while on normal tissues from patients with periodontal disease, it was $8.8 \% \pm 5.7$. The discrepancy in the mean of methylation between periodontitis sites in comparison with healthy group at baseline was statistically significant $(p=.03$ for periodontitis sites versus healthy group). Following periodontal treatment, methylation percentage decreased dramatically in periodontitis sites, at 2 weeks, almost to half $(5.8 \% \pm 3.2, p<.001$ versus baseline), with a very slight rise from 2 to 8 weeks ( $7.2 \% \pm 4.3, p=.004$ versus baseline), which was comparable to the methylation level reported in the healthy group. On the contrary, the mean percentage of methylation steadily declined in normal sites, reaching $5 \% \pm 1.9$ at 8 weeks, $p=.03$ versus baseline).

To evaluate the DNA methylation at a broader level, we explored the methylation profile of LINE-1 promoter region. We observed that the mean percentage of methylation was similar between the healthy group $(69.5 \% \pm 3.5)$ and normal sites in diseased patients $(69.4 \% \pm 2.1)$ and remained fairly stable during the observation period. As for periodontitis sites, a slight increase in the methylation of the promoter region at 8 weeks was observed $(71.7 \% \pm 2.8$ versus $70.2 \% \pm 2.8$ at baseline). These findings were not statistically significant ( $p$-value $>.05$ ).

Mean methylation percentages of the selected genes and $p$-values are summarized in Table 4. Time pattern of DNA Methylation among different groups for TNF- $\alpha$, IFN- $\gamma$, COX-2 and LINE-1 are demonstrated in Figure 2.

\section{4 | DISCUSSION}

Here, we provide for the first-time evidence of epigenetic modifications mediated by periodontal therapy. Due to the well-established association 


\begin{tabular}{|c|c|c|c|}
\hline $\begin{array}{l}\text { Demographic/clinical } \\
\text { characteristics }\end{array}$ & Healthy $(n=10)$ & $\begin{array}{l}\text { Periodontal disease } \\
(n=10)\end{array}$ & $p$-value ${ }^{a}$ \\
\hline Males/females & $5 / 5$ & $3 / 7$ & 0.36 \\
\hline $\begin{array}{l}\text { Age (years) } \\
\text { (Mean } \pm S D)\end{array}$ & $53.3 \pm 12.3$ & $46.6 \pm 10.0$ & 0.11 \\
\hline \multirow{3}{*}{$\begin{array}{l}\text { Periodontal probing depth }(\mathrm{mm}) \\
(\text { Mean } \pm S D)\end{array}$} & \multirow[t]{3}{*}{$\leq 3$ (at baseline) } & $4.2 \pm 0.4$ (at baseline) & ND \\
\hline & & $\begin{array}{l}2.9 \pm 0.4 \text { ( } 2 \text { weeks after } \\
\text { periodontal treatment) }\end{array}$ & $p<.001$ \\
\hline & & $\begin{array}{r}2.5 \pm 0.3 \text { ( } 8 \text { weeks after } \\
\text { periodontal treatment) }\end{array}$ & $p<.001$ \\
\hline \multirow{3}{*}{$\begin{array}{l}\text { Clinical attachment level }(\mathrm{mm}) \\
(\text { Mean } \pm S D)\end{array}$} & \multirow[t]{3}{*}{$\leq 3$} & $4.2 \pm 0.9$ (at baseline) & ND \\
\hline & & $\begin{array}{l}3.9 \pm 1.2 \text { ( } 2 \text { weeks after } \\
\text { periodontal treatment) }\end{array}$ & $p=.21$ \\
\hline & & $\begin{array}{r}3.6 \pm 0.9 \text { ( } 8 \text { weeks after } \\
\text { periodontal treatment) }\end{array}$ & $p=.01$ \\
\hline \multirow{3}{*}{$\begin{array}{l}\text { Bleeding on probing (\%) } \\
\text { (Mean } \pm S D)\end{array}$} & \multirow[t]{3}{*}{$0 \%$} & $63 \pm 25 \%$ (at baseline) & ND \\
\hline & & $\begin{array}{l}7 \pm 6 \% \text { ( } 2 \text { weeks after } \\
\text { periodontal treatment) }\end{array}$ & $p<.001$ \\
\hline & & $\begin{array}{l}5 \pm 6 \% \text { ( } 8 \text { weeks after } \\
\text { periodontal treatment) }\end{array}$ & $p<.001$ \\
\hline
\end{tabular}

ND, not determined.

${ }^{a}$ For gender and age, $p$-values were calculated by chi-squared and Wilcoxon-Mann-Whitney test, respectively. For periodontal variables, $p$-values were obtained from random-intercept linear regression model.

\begin{tabular}{|c|c|c|c|}
\hline Biopsy site & At baseline & $\begin{array}{l}\text { Two weeks after } \\
\text { periodontal treatment }\end{array}$ & $\begin{array}{l}\text { Eight weeks after } \\
\text { periodontal treatment }\end{array}$ \\
\hline \multicolumn{4}{|l|}{$\mathrm{PPD}($ mean $\pm S D)$} \\
\hline \multirow{2}{*}{$\begin{array}{l}\text { Periodontal } \\
\text { disease/normal } \\
\text { sites }\end{array}$} & \multirow[t]{2}{*}{$3.0 \pm 0.0$} & $2.8 \pm 0.4$ & $2.7 \pm 0.5$ \\
\hline & & $p=.18$ versus baseline & $p=.03$ versus baseline \\
\hline \multirow{2}{*}{$\begin{array}{l}\text { Periodontal } \\
\text { disease/ } \\
\text { periodontitis } \\
\text { sites }\end{array}$} & $7.1 \pm 1.7$ & $5.5 \pm 0.8$ & $4.4 \pm 0.9$ \\
\hline & $\begin{array}{c}p<.001 \text { versus } \\
\text { normal sites }\end{array}$ & $p<.001$ versus baseline & $p<.001$ versus baseline \\
\hline \multicolumn{4}{|l|}{$\mathrm{CAL}($ mean $\pm S D)$} \\
\hline \multirow{2}{*}{$\begin{array}{l}\text { Periodontal } \\
\text { disease/normal } \\
\text { sites }\end{array}$} & \multirow[t]{2}{*}{$3.6 \pm 0.8$} & $3.6 \pm 1.0$ & $3.4 \pm 1.9$ \\
\hline & & $p=1.00$ versus baseline & $p=.72$ versus baseline \\
\hline \multirow{2}{*}{$\begin{array}{l}\text { Periodontal } \\
\text { disease/ } \\
\text { periodontitis } \\
\text { sites }\end{array}$} & $8.4 \pm 2.6$ & $7.7 \pm 2.5$ & $5.6 \pm 2.5$ \\
\hline & $\begin{array}{c}p<.001 \text { versus } \\
\text { normal sites }\end{array}$ & $p=.23$ versus baseline & $p<.001$ versus baseline \\
\hline
\end{tabular}

$p$-values calculated with random-intercept linear regression models.
TABLE 2 Patient demographic and clinical characteristics
TABLE 3 Clinical characteristics of biopsied sites in the periodontitis group, at baseline, 2 and 8 weeks following periodontal therapy of methylation with stable gene regulation, we chose to evaluate the status of DNA methylation instead of the acetylation of genes related to inflammation (Bäckdahl et al., 2009). Our study shows the expression pattern of methylated genes before periodontal therapy and during the 2 months follow-up. As alterations in the methylation patterns might vary from site to site within the same individual (Barros \& Offenbacher, 2014), we assessed the epigenetic modifications in normal and periodontitis sites within the same patient with chronic periodontitis. We also compared our data to tissue samples from healthy periodontium. Our study gave emphasis to the methylation status of TNF- $\alpha$, IFN- $\gamma$ and COX-2, as key genes associated with periodontal disease progression. We also carefully selected LINE-1 gene as a genome-wide readout for methylation. Of note, our cohort of patients includes Caucasians, and careful interpretation of the results must take into consideration the potential ethnic influence over epigenetic modifications (Kwabi-Addo et al., 2010; Straughen, Sipahi, Uddin, Misra, \& Misra, 2015). 
TABLE 4 Methylation of LINE-1, COX-2, IFN- $\gamma$ and TNF- $\alpha$ genes across groups and over time ${ }^{a}$

\begin{tabular}{|c|c|c|c|c|}
\hline \multirow[b]{2}{*}{ Genes } & \multirow[b]{2}{*}{ Group } & \multicolumn{3}{|c|}{ Methylation percentage (Mean $\pm S D$ ) } \\
\hline & & At baseline & $\begin{array}{l}\text { Two weeks after } \\
\text { periodontal treatment }\end{array}$ & $\begin{array}{l}\text { Eight weeks after } \\
\text { Periodontal treatment }\end{array}$ \\
\hline \multirow[t]{5}{*}{ TNF- $\alpha$} & Healthy & $36.6 \pm 9.2$ & - & - \\
\hline & \multirow{2}{*}{$\begin{array}{l}\text { Periodontal } \\
\text { disease/ } \\
\text { normal sites }\end{array}$} & $34.1 \pm 5.2$ & $33.9 \pm 6.5$ & $34.0 \pm 9.3$ \\
\hline & & $\begin{array}{l}p=.44 \\
\text { versus } \\
\text { healthy }\end{array}$ & $p=.92$ versus baseline & $p=.90$ versus baseline \\
\hline & \multirow{2}{*}{$\begin{array}{l}\text { Periodontal } \\
\text { disease/ } \\
\text { periodontitis } \\
\text { sites }\end{array}$} & $31.4 \pm 7.8$ & $31.5 \pm 8.5$ & $33.7 \pm 7.4$ \\
\hline & & $\begin{array}{l}p=.11 \\
\text { versus } \\
\text { healthy }\end{array}$ & $p=.97$ versus baseline & $p=.50$ versus baseline \\
\hline \multirow[t]{5}{*}{ IFN- $\gamma$} & Healthy & $88.6 \pm 1.4$ & - & - \\
\hline & \multirow{2}{*}{$\begin{array}{l}\text { Periodontal } \\
\text { disease/ } \\
\text { normal sites }\end{array}$} & $85.8 \pm 6.5$ & $87.7 \pm 3.5$ & $88.8 \pm 2.8$ \\
\hline & & $\begin{array}{l}p=.10 \\
\text { versus } \\
\text { healthy }\end{array}$ & $p=.33$ versus baseline & $p=.14$ versus baseline \\
\hline & \multirow{2}{*}{$\begin{array}{l}\text { Periodontal } \\
\text { disease/ } \\
\text { periodontitis } \\
\text { sites }\end{array}$} & $88.3 \pm 2.1$ & $88.4 \pm 2.2$ & $86.2 \pm 3.8$ \\
\hline & & $\begin{array}{l}p=.85 \\
\text { versus } \\
\text { healthy }\end{array}$ & $p=.89$ versus baseline & $p=.08$ versus baseline \\
\hline \multirow[t]{5}{*}{$\operatorname{cox}-2$} & Healthy & $6.7 \pm 7.6$ & - & - \\
\hline & \multirow{2}{*}{$\begin{array}{l}\text { Periodontal } \\
\text { disease/ } \\
\text { normal sites }\end{array}$} & $8.8 \pm 5.7$ & $6.6 \pm 3.6$ & $5.0 \pm 1.9$ \\
\hline & & $\begin{array}{l}p=.47 \\
\text { versus } \\
\text { healthy }\end{array}$ & $p=.18$ versus baseline & $p=.03$ versus baseline \\
\hline & \multirow{2}{*}{$\begin{array}{l}\text { Periodontal } \\
\text { disease/ } \\
\text { periodontitis } \\
\text { sites }\end{array}$} & $13.2 \pm 7.3$ & $5.8 \pm 3.2$ & $7.2 \pm 4.3$ \\
\hline & & $\begin{array}{l}p=.03 \\
\text { versus } \\
\text { healthy }\end{array}$ & $p<.001$ versus baseline & $\begin{array}{l}p=.004 \text { versus } \\
\text { baseline }\end{array}$ \\
\hline \multirow[t]{5}{*}{ LINE-1 } & Healthy & $69.5 \pm 3.5$ & - & - \\
\hline & \multirow{2}{*}{$\begin{array}{l}\text { Periodontal } \\
\text { disease/ } \\
\text { normal sites }\end{array}$} & $69.4 \pm 2.1$ & $70.0 \pm 2.3$ & $69.5 \pm 1.4$ \\
\hline & & $\begin{array}{l}p=.92 \\
\text { versus } \\
\text { healthy }\end{array}$ & $p=.36$ versus baseline & $p=.91$ versus baseline \\
\hline & \multirow{2}{*}{$\begin{array}{l}\text { Periodontal } \\
\text { disease/ } \\
\text { periodontitis } \\
\text { sites }\end{array}$} & $70.2 \pm 2.8$ & $70.7 \pm 2.8$ & $71.7 \pm 2.8$ \\
\hline & & $\begin{array}{l}p=.58 \\
\text { versus } \\
\text { healthy }\end{array}$ & $p=.61$ versus baseline & $p=.22$ versus baseline \\
\hline
\end{tabular}

$p$-values calculated with random-intercept linear regression models.

${ }^{a}$ The sample size was 10 in each group-moment combinations, except for 8 weeks (one subject lost to follow-up).
Findings of this study showed that periodontal therapy significantly reduced COX-2 methylation levels comparable to healthy individuals at both 2 and 8 weeks after treatment. The methylation status of the COX-2 gene (also known as prostaglandin-endoperoxide synthase 2 or PTGS2) was inspected because it is the enzyme that synthesizes prostaglandin E2 (PGE2) and governs its production. As is known, PGE2 is a key inflammatory mediator in periodontal disease and is well correlated with periodontal inflammation and alveolar bone loss (Goodson, Dewhirst, \& Brunetti, 1974; Noguchi \& Ishikawa, 2007; Offenbacher et al., 1992; Reynolds,
Prudencio, Aichelmann-Reidy, Woodward, \& Uhrich, 2007; Tipton, Flynn, Stein, \& Dabbous, 2003). We found that COX-2 gene promoter was hypomethylated in biopsies retrieved from the healthy group (6.7\%), while DNA methylation was as twice higher in the periodontitis sites of the periodontal disease group (13.2\%). Similarly, Loo, Jin, Cheung, Wang, and Chow (2010) described a hypermethylated COX-2 in 19\% of patients with chronic periodontitis. In concordance, Zhang, Barros, et al. (2010) identified a hypermethylated PTGS2 promoter in periodontal disease tissues, associated with lower levels of PTGS2 transcription. Therefore, high 

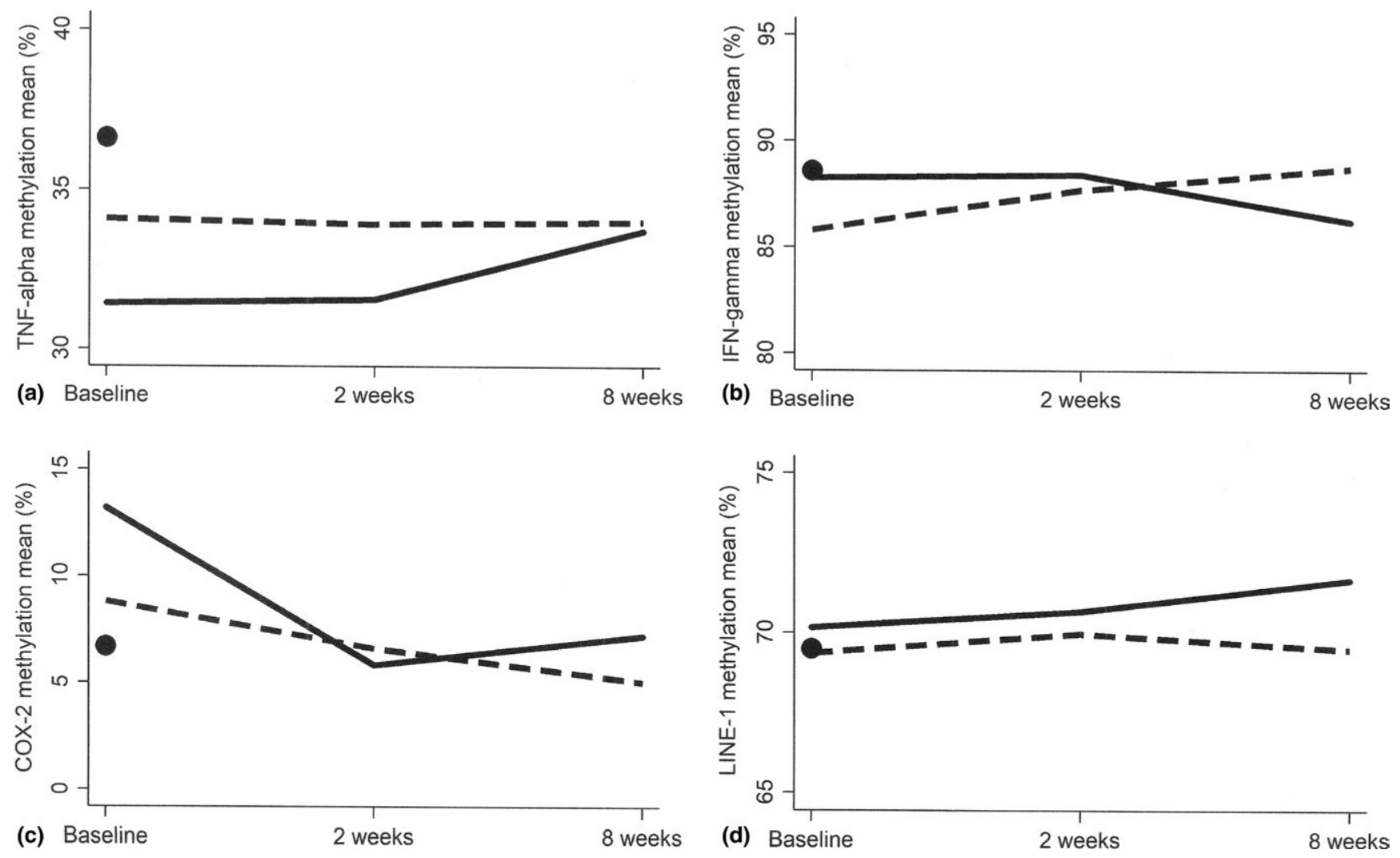

FIGURE 2 Time pattern of DNA Methylation among different groups for TNF- $\alpha$ (a), IFN- $\gamma$ (b), COX-2 (c) and LINE-1 (d). Circle represents healthy groups, intermittent line represents healthy sites in periodontitis group and solid line represents periodontitis sites in periodontitis group

levels of COX-2 methylation can render an intrinsic protective mechanism capable of preventing the unrestrained breakdown of the periodontium (Zhang, Barros, et al., 2010). However, it must be noted that the methylation frequency of the COX-2 gene promoter was much higher in our study than that reported by Zhang, Barros, et al. (2010); $6.7 \%$ versus $0.85 \%$ in the healthy sites and $13.2 \%$ versus $4.3 \%$ in the periodontitis-affected sites, as they measured DNA methylation of the COX-2 gene promoter using a different technique, that is bisulphite specific PCR, cloning and sequencing.

Other findings in literature might further confirm the downregulation of COX-2 in the state of chronic disease; in a previously published crosssectional epidemiological study, the attachment level was negatively associated with the levels of $\mathrm{PGE}_{2}$ in the gingival crevicular fluid (GCF) (Zhong, Slade, Beck, \& Offenbacher, 2007). Hence, it was suggested that chronic inflammation might serve as a new "set-point" in which certain inflammatory mediators are downregulated to prevent unrestricted destruction of periodontal tissues (Zhang, Barros, et al., 2010).

Regarding other biomarkers, findings of the present clinical investigation revealed that periodontal therapy did not influence DNA methylation of TNF- $\alpha$, IFN- $\gamma$ and LINE- 1 levels at normal and periodontitis sites over time ( $p>.05)$, indicating that epigenetic alterations might be locally sustained for some mediators even after the elimination of periodontal inflammation. Nonetheless, certain observations can still be underlined; DNA methylation status of TNF- $\alpha$ gene promoter was almost stable in normal sites throughout the evaluation period and was not restored to that of the healthy group. This might indicate a different methylation profile in healthy tissues of individuals with and without history of periodontitis. Such information might help to better elucidate disease development in healthy sites in susceptible periodontitis patients, which needs to be further investigated for implementing appropriate intervention plans (Mdala et al., 2014). However, this hypothesis needs to be confirmed in future studies exploring a wide panel of inflammatory cytokines. TNF- $\alpha$ gene was selected for DNA methylation analysis due to its important role in the pathogenesis of periodontal disease and tissue destruction (Page, 1991).

With respect to IFN- $\gamma$ gene promoter, hypermethylation was evident among all entities even after periodontal therapy, which might be a usual feature in healthy and inflamed periodontal tissues. In fact, hypermethylation of IFN- $\gamma$ gene promoter has already been reported in another study (Viana et al., 2011) probably due to the presence of distinctly active mixed cell population in the sample as previously suggested (Stefani et al., 2013; Winders, Schwartz, \& Bruniquel, 2004). IFN- $\gamma$ gene was evaluated in the present study because of its association with the severity and progression of periodontal disease (Garlet, Martins, Ferreira, Milanezi, \& Silva, 2003).

For each gene, CpG positions were selected based on previously published data (Dawsey et al., 2008; Madrigano et al., 2012; Cantone et al., 2017), as they are more consistent in terms of repeatability of the assay. Four CpG islands were analysed for COX-2 and TNF- $\alpha$ genes while two were assessed for IFN- $\gamma$ gene. Although higher number of $\mathrm{CpG}$ islands was reported in literature for these genes (Zhang, Crivello, et al., 2010; Zhang, Barros, et al., 2010; Zhang et al., 2013), this can be attributed to the different technique utilized for DNA methylation analysis in the noted studies. Our clinical investigation is a pilot study, and with the limited 
amount of available tissues, we were more interested in evaluating DNA methylation of more genes than covering the entire promoter of one single gene. Furthermore, we were not able to cover a larger sequence due to the limited amount of harvested tissues.

LINE-1 was selected to evaluate the DNA methylation more comprehensively, as it encloses a high CpG density and comprises about 17\% of the genome (Kitkumthorn \& Mutirangura, 2011; Newman et al., 2012) with the total genomic methylation content being consistent with the methylation of such repetitive elements (Lange et al., 2012). Despite the lack of statistically significant findings, LINE-1 hypermethylation was maintained in normal and periodontitis sites, overtime, reflecting an overall genome stability.

Based on the findings of the present study, we can conclude that: (i) periodontal therapy is not sufficient to reset the methylation levels of TNF- $\alpha$ and IFN- $\gamma$ inflammatory genes to levels of healthy patients; (ii) periodontal therapy is sufficient to reset the levels of COX-2 methylation to compatible levels observed in healthy patients; (iii) the methylation profile from normal tissues suggests that unaffected sites from patients with periodontal disease might be more prone to periodontal tissue breakdown; (iv) epigenetic modifications result in the activation of downregulatory mechanisms to prevent unrestricted periodontal tissue destruction; and finally $(v)$ on a global methylation perspective, hypermethylation of LINE-1 was maintained in periodontitis and normal sites, overtime.

The results of the study should be interpreted with caution as it has certain limitations. Gingival biopsies of normal and inflamed tissues were harvested from different sites and not the same one during different points of time. Sample collection from the same site is preferable when evaluating the influence of periodontal therapy over time, however, that was not possible because 2 weeks after periodontal therapy, soft tissues at the biopsy site were not completely healed. Another study limitation is the lack of longitudinal data on the healthy subjects as it only captured the temporal changes in the chronic periodontitis group; it was not possible to harvest multiple biopsies for healthy participants from an ethical standpoint. Simultaneous analysis of DNA methylation and mRNA expression could have strengthened the consistency of our findings. However, the limited amount of tissue recovered from tissue biopsies, and the difficulty of collecting larger samples especially in control subjects did not allow for DNA and RNA analysis in the same subject. Also, limited numbers of CpG sites were analysed in our pilot study, despite being the same positions previously reported in literature. Hence, future studies are needed to allow us cover all the $\mathrm{CpG}$ sites within the promoter region.

Findings of this investigation represent data on the short-term; thus, epigenetic changes still need to be monitored on the long-term to understand if the methylation status in chronic periodontitis could turn out similar to that in healthy individuals with no history of periodontitis, following an effective periodontal therapy, maintenance and compliance.

\section{5 | CONCLUSIONS}

Periodontal therapy was able to reset the DNA methylation status of COX-2 gene in patients with chronic periodontitis, while DNA methylation levels of TNF- $\alpha, \mathrm{IFN}-\gamma$ and LINE-1 were sustained in the periodontal disease group even after periodontal therapy. These findings suggest that the local effects of the disease have an influence on the epigenetics of the tissues that may be modulated by environmental factors, including the microbiota. Future investigations should further explore the identification of specific factors that affect the local epigenetics of periodontal soft and hard tissues. Moreover, future studies need to consider an expanded panel of inflammationassociated epigenetic changes over time in periodontal diseases.

\section{CONFLICT OF INTEREST}

The authors report no conflict of interest.

\section{REFERENCES}

Adcock, I. M., Tsaprouni, L., Bhavsar, P., \& Ito, K. (2007). Epigenetic regulation of airway inflammation. Current Opinion in Immunology, 19, 694-700.

Andia, D. C., de Oliveira, N. F. P., Casarin, R. C. V., Casati, M. Z., Line, S. R. P., \& de Souza, A. P. (2010). DNA methylation status of the IL8 gene promoter in aggressive periodontitis. Journal of Periodontology, 81, 1336-1341.

Andia, D. C., Planello, A. C., Portinho, D., da Silva, R. A., Salmon, C. R., Sallum, E. A., ... de Souza, A. P. (2015). DNA methylation analysis of SOCS1, SOCS3, and LINE-1 in microdissected gingival tissue. Clinical Oral Investigations, 19, 2337-2344.

Armitage, G. C. (1999). Development of a classification system for periodontal diseases and conditions. Annals of Periodontology, 4, 1-6.

Bäckdahl, L., Bushell, A., \& Beck, S. (2009). Inflammatory signalling as mediator of epigenetic modulation in tissue-specific chronic inflammation. International Journal of Biochemistry and Cell Biology, 41, 176-184.

Barros, S. P., \& Offenbacher, S. (2014). Modifiable risk factors in periodontal disease: Epigenetic regulation of gene expression in the inflammatory response. Periodontology 2000, 64, 95-110.

Bird, A. (2002). DNA methylation patterns and epigenetic memory. Genes and Development, 16, 6-21.

Bollati, V., Baccarelli, A., Hou, L., Bonzini, M., Fustinoni, S., Cavallo, D., ... Yang, A. S. (2007). Changes in DNA methylation patterns in subjects exposed to low-dose benzene. Cancer Research, 67, 876-880.

Borrell, L. N., \& Papapanou, P. N. (2005). Analytical epidemiology of periodontitis. Journal of Clinical Periodontology, 32, 132-158.

Cantone, L., lodice, S., Tarantini, L., Albetti, B., Restelli, I., Vigna, L., ... Bollati, V. (2017). Particulate matter exposure is associated with inflammatory gene methylation in obese subjects. Environmental Research, 152, 478-484.

Dawsey, S. P., Roth, M. J., Adams, L., Hu, N., Wang, Q. H., Taylor, P. R., \& Woodson, K. (2008). COX-2 (PTGS2) gene methylation in epithelial, subepithelial lymphocyte and stromal tissue compartments in a spectrum of esophageal squamous neoplasia. Cancer Detection and Prevention, 32, 135-139.

El Gazzar, M., Yoza, B. K., Hu, J. Y.-Q., Cousart, S. L., \& McCall, C. E. (2007). Epigenetic silencing of tumor necrosis factor alpha during endotoxin tolerance. The Journal of Biological Chemistry, 282, 26857-26864.

Fitzpatrick, D. R., \& Wilson, C. B. (2003). Methylation and demethylation in the regulation of genes, cells, and responses in the immune system. Clinical Immunology, 109, 37-45.

Garlet, G. P., Martins, W. Jr, Ferreira, B. R., Milanezi, C. M., \& Silva, J. S. (2003). Pattern of chemokine receptors expression in different forms of human periodontal disease. Journal of Periodontal Research, 38, 210-217.

Goodson, J. M., Dewhirst, F. E., \& Brunetti, A. (1974). Prostaglandin E2 levels and human periodontal disease. Prostaglandins, 6, 81-85.

Ishida, K., Kobayashi, T., Ito, S., Komatsu, Y., Yokoyama, T., Okada, M., ... Yoshie, H. (2012). Interleukin-6 gene promoter methylation in 
rheumatoid arthritis and chronic periodontitis. Journal of Periodontology, 83, 917-925.

Kitkumthorn, N., \& Mutirangura, A. (2011). Long interspersed nuclear element-1 hypomethylation in cancer: Biology and clinical applications. Clinical Epigenetics, 2, 315-330.

Kojima, A., Kobayashi, T., Ito, S., Murasawa, A., Nakazono, K., \& Yoshie, H. (2016). Tumor necrosis factor-alpha gene promoter methylation in Japanese adults with chronic periodontitis and rheumatoid arthritis. Journal of Periodontal Research, 51, 350-358.

Kornman, K. S. (2008). Mapping the pathogenesis of periodontitis: A new look. The Journal of Periodontology, 79, 1560-1568.

Kwabi-Addo, B., Wang, S., Chung, W., Jelinek, J., Patierno, S. R., Wang, B. D., ... Ittmann, M. (2010). Identification of differentially methylated genes in normal prostate tissues from African American and Caucasian men. Clinical Cancer Research, 16, 3539-3547.

Lange, N. E., Sordillo, J., Tarantini, L., Bollati, V., Sparrow, D., Vokonas, P., ... Demeo, D. L. (2012). Alu and LINE-1 methylation and lung function in the normative ageing study. British Medical Journal Open, 2, e001231.

Larsson, L., Castilho, R. M., \& Giannobile, W. V. (2015). Epigenetics and its role in periodontal diseases: A state-of-the-art review. Journal of Periodontology, 86, 556-568.

Lod, S., Johansson, T., Abrahamsson, K. H., \& Larsson, L. (2014). The influence of epigenetics in relation to oral health. International Journal of Dental Hygiene, 12, 48-54.

Loo, W. T. Y., Jin, L., Cheung, M. N. B., Wang, M., \& Chow, L. W. C. (2010). Epigenetic change in E-cadherin and COX-2 to predict chronic periodontitis. Journal of Translational Medicine, 8, 110.

Madrigano, J., Baccarelli, A., Mittleman, M. A., Sparrow, D., Vokonas, P. S., Tarantini, L., \& Schwartz, J. (2012). Aging and epigenetics: Longitudinal changes in gene-specific DNA methylation. Epigenetics, 7, 63-70.

Martins, M. D., Jiao, Y., Larsson, L., Almeida, L. O., Garaicoa-Pazmino, C., Le, J. M., ... Castilho, R. M. (2016). Epigenetic modifications of histones in periodontal disease. Journal of Dental Research, 95, 215-222.

Mdala, I., Olsen, I., Haffajee, A. D., Socransky, S. S., Thoresen, M., \& De Blasio, B. F. (2014). Comparing clinical attachment level and pocket depth for predicting periodontal disease progression in healthy sites of patients with chronic periodontitis using multi-state Markov models. Journal of Clinical Periodontology, 41, 837-845.

Newman, M. R., Blyth, B. J., Hussey, D. J., Jardine, D., Sykes, P. J., \& Ormsby, R. J. (2012). Sensitive quantitative analysis of murine LINE1 DNA methylation using high resolution melt analysis. Epigenetics, 7, 92-105.

Ngollo, M., Dagdemir, A., Karsli-Ceppioglu, S., Judes, G., Pajon, A., PenaultLlorca, F., ... Bernard-Gallon, D. J. (2014). Epigenetic modifications in prostate cancer. Epigenomics, 6, 415-426.

Noguchi, K., \& Ishikawa, I. (2007). The roles of cyclooxygenase-2 and prostaglandin E2 in periodontal disease. Periodontology 2000, 43, 85-101.

Offenbacher, S., Williams, R. C., Jeffcoat, M. K., Howell, T. H., Odle, B. M., Smith, M. A., ... Goldhaber, P. (1992). Effects of NSAID on beagle crevicular cyclooxygenase metabolites periodontal bone loss. Journal of Periodontal Research, 27, 207-213.

Oliveira, N. F. P., Damm, G. R., Andia, D. C., Salmon, C., Nociti, F. H., Line, S. R. P., \& De Souza, A. P. (2009). DNA methylation status of the IL8 gene promoter in oral cells of smokers and non-smokers with chronic periodontitis. Journal of Clinical Periodontology, 36, 719-725.

Page, R. C. (1991). The role of inflammatory mediators in the pathogenesis of periodontal disease. Journal of Periodontal Research, 26, 230-242.

Rabe-Hesketh, S., \& Skrondal, A. (2008) Multilevel and longitudinal modeling using stata (2nd edn). College Station, TX, USA: Stata Press.

Reynolds, M. A., Prudencio, A., Aichelmann-Reidy, M. E., Woodward, K., \& Uhrich, K. E. (2007). Non-steroidal anti-inflammatory drug (NSAID)derived poly(anhydride-esters) in bone and periodontal regeneration. Current Drug Delivery, 4, 233-239.

Schulz, S., Immel, U. D., Just, L., Schaller, H. G., Gläser, C., \& Reichert, S. (2016). Epigenetic characteristics in inflammatory candidate genes in aggressive periodontitis. Human Immunology, 77, 71-75.
Segelnick, S. L., \& Weinberg, M. A. (2006). Reevaluation of initial therapy: When is the appropriate time? Journal of Periodontology, 77, 1598-1601.

Shaw, R. (2006). The epigenetics of oral cancer. International Journal of Oral and Maxillofacial Surgery, 35, 101-108.

Stefani, F. A., Viana, M. B., Dupim, A. C., Brito, J. A., Gomez, R. S., da Costa, J. E., \& Moreira, P. R. (2013). Expression, polymorphism and methylation pattern of interleukin-6 in periodontal tissues. Immunobiology, 218, 1012-1017.

Straughen, J. K., Sipahi, L., Uddin, M., Misra, D. P., \& Misra, V. K. (2015). Racial differences in IGF1 methylation and birth weight. Clinical Epigenetics, 7, 47.

Takashiba, S., \& Naruishi, K. (2006). Gene polymorphisms in periodontal health and disease. Periodontology 2000, 40, 94-106.

Tarantini, L., Bonzini, M., Tripodi, A., Angelici, L., Nordio, F., Cantone, L., ... Baccarelli, A. A. (2013). Blood hypomethylation of inflammatory genes mediates the effects of metal-rich airborne pollutants on blood coagulation. Occupational and Environmental Medicine, 70, 418-425.

Tipton, D. A., Flynn, J. C., Stein, S. H., \& Dabbous, Mk. (2003). Cyclooxygenase-2 inhibitors decrease interleukin-1beta-stimulated prostaglandin E2 and IL-6 production by human gingival fibroblasts. Journal of Periodontology, 74, 1754-1763.

Tonetti, M. S., Claffey, N., European Workshop in Periodontology Group C. (2005). Advances in the progression of periodontitis and proposal of definitions of a periodontitis case and disease progression for use in risk factor research. Group C consensus report of the 5th European Workshop in Periodontology. Journal of Clinical Periodontology, 32, 210-213.

Van Dyke, T. E., \& van Winkelhoff, A. J. (2013). Infection and inflammatory mechanisms. Journal of Periodontology, 84, S1-S7.

Viana, M. B., Cardoso, F. P., Diniz, M. G., Costa, F. O., da Costa, J. E., Gomez, R. S., \& Moreira, P. R. (2011). Methylation pattern of IFN- $\gamma$ and IL-10 genes in periodontal tissues. Immunobiology, 216, 936-941.

Wilson, A. G. (2008). Epigenetic regulation of gene expression in the inflammatory response and relevance to common diseases. Journal of Periodontology, 79, 1514-1519.

Winders, B. R., Schwartz, R. H., \& Bruniquel, D. A. (2004). A distinct region of the murine INF- promoter is hypomethylated from early $T$ cell development through mature naive and Th1cell differentiation, but is hypermethylation in Th2 cells. Journal of Immunology, 173, 7377-7384.

Zhang, S., Barros, S. P., Moretti, A. J., Yu, N., Zhou, J., Preisser, J. S., ... Offenbacher, S. (2013). Epigenetic regulation of TNFA expression in periodontal disease. Journal of Periodontology, 84, 1606-1616.

Zhang, S., Barros, S. P., Niculescu, M. D., Moretti, A. J., Preisser, J. S., \& Offenbacher, S. (2010). Alteration of PTGS2 promoter methylation in chronic periodontitis. Journal of Dental Research, 89, 133-137.

Zhang, S., Crivello, A., Offenbacher, S., Moretti, A., Paquette, D. W., \& Barros, S. P. (2010). Interferon-gamma promoter hypomethylation and increased expression in chronic periodontitis. Journal of Clinical Periodontology, 37, 953-961.

Zhong, Y., Slade, G. D., Beck, J. D., \& Offenbacher, S. (2007). Gingival crevicular fluid interleukin-1beta, prostaglandin E2 and periodontal status in a community population. Journal of Clinical Periodontology, 34, 285-293.

How to cite this article: Asa'ad F, Bollati V, Pagni G, et al. Evaluation of DNA methylation of inflammatory genes following treatment of chronic periodontitis: A pilot casecontrol study. J Clin Periodontol. 2017;44:905-914. https://doi.org/10.1111/jcpe.12783 